\title{
Abnormal gastric adaptive relaxation in patients with gastrooesophageal reflux
}

\author{
M N Hartley, S J Walker, C R Mackie
}

\begin{abstract}
Gastric adaptive relaxation was measured in $\mathbf{1 5}$ healthy volunteers (control group) and in 12 patients with symptomatic gastrooesophageal reflux confirmed by 24 hour $\mathrm{pH}$ monitoring (reflux group). The control group were: 13 men, two women; median age 30 years, range 22-41; median body weight $70 \mathrm{~kg}$, range 50-79 kg. All were asymptomatic on no medication. The reflux group were: eight men, four women, median age 48 years, range 23-65; median body weight $77 \mathrm{~kg}$, range $60-92 \mathrm{~kg}$. Medication was withheld for 12 hours before the study. Endoscopy showed no abnormality in five patients, oesophagitis in three patients and oesophagitis with hiatus hernia in four patients. Fasted subjects were intubated with a Ryle's tube containing a pressure microtransducer within a flaccid plastic bag $(800 \mathrm{ml})$. Gastric corpus-fundus pressure was recorded during distension of the bag with $460(20) \mathrm{ml}$ mean (SD) of air over 30 seconds. Pressure indices (median: range) derived from areas under the pressure curves during distension were: - control: $12.7(7 \cdot 5-17 \cdot 1) \mathrm{cm} \mathrm{H}_{2} \mathrm{O}$; reflux: 9.1 (6.4-13.3) $\mathrm{cm} \mathrm{H}_{2} \mathrm{O}, \mathrm{p}<0.01$ (Mann Whitney $U$ test). Similar results were obtained from pressure indices derived from recordings during the immediate postdistension period. No correlation was found between pressure indices and age, sex or body weight. The results indicate that the gastric pressure response to distension is reduced in patients with gastrooesophageal reflux.
\end{abstract}

Motor abnormalities of the oesophagus and stomach have been identified in patients with gastrooesophageal reflux using radionuclide and manometric techniques. These include delayed bolus transit ${ }^{12}$ and weak peristalsis ${ }^{3}$ in the oesophageal body, and low sphincter pressures and frequent transient sphincter relaxations ${ }^{5}$ within the lower oesophageal high pressure zone. Studies of gastric function have shown delayed gastric emptying ${ }^{6}$ and decreased antral motility in some patients with gastrooesophageal reflux.

Motor function of the corpus-fundus region of the stomach has received little attention in relation to the pathophysiology of gastrooesophageal reflux. It is this region of the stomach, adjacent to the lower oesophageal sphincter, that is involved in the accommodation of a meal and the control of intragastric pressure.
It seems reasonable to suppose that the occurrence of reflux of stomach contents into the oesophagus requires a gastrooesophageal luminal pressure gradient at the moment of reflux. In theory, therefore, a disturbance in the control of intragastric pressure may play a role in the pathogenesis of gastrooesophageal reflux. Gastric adaptive relaxation is a specialised motor function of the gastric corpus-fundus; the stomach adapts to the distending volume with minimal rise in intragastric pressure. ${ }^{8}$ In order to explore the possible role of disordered gastric adaptive relaxation in gastrooesophageal reflux disease we have modified the dynamic technique of Jahnberg $e t a l^{8}$ to include also the static technique of Stadaas ${ }^{9}$ and have studied gastric adaptive relaxation in a group of healthy volunteers and a group of patients with symptomatic gastrooesophageal reflux. The study was formally approved by the Royal Liverpool Hospital Ethical Committee in November 1985. Written informed consent was given by all subjects studied.

\section{Methods}

\section{SUBJECTS}

Fifteen normal healthy volunteers were studied. These were 13 men and two women, with a median age of 30 years (range 22-41) and a median body weight of $70 \mathrm{~kg}$ (range $50-79$ ) kg. Twelve patients with symptomatic gastrooesophageal reflux were studied. They were eight men and four women, with a median age of 48 years (range 23-65) and a median body weight of $77 \mathrm{~kg}$ (range $60-92 \mathrm{~kg}$ ). All subjects in the control group were asymptomatic. Among patients in the reflux group, eight were complaining of regurgitation, 11 of heartburn, and four of dysphagia.

The presence of pathological gastrooesophageal reflux was confirmed in all patients in the reflux group by 24 hour ambulatory oesophageal pH monitoring. Pathological gastrooesophageal reflux was defined as the presence of one or more of the following criteria: total reflux time greater than $6 \%$, erect reflux time greater than $8 \%$, supine reflux time greater than $2 \%$; more than two reflux episodes longer than five minutes. A reflux episode was defined as a drop in $\mathrm{pH}$ to 4 or less.

Endoscopy showed macroscopic oesophagitis in seven patients, associated with a hiatus hernia 


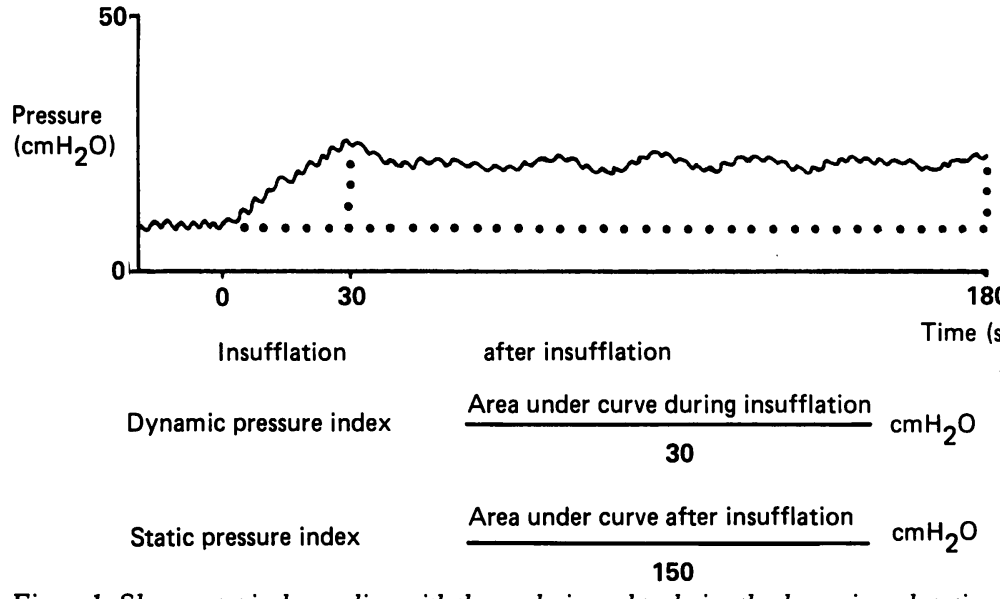

Figure 1: Shows a typical recording with the analysis used to derive the dynamic and static pressure indices. in four patients. Five patients had no abnormality at endoscopy. None of the subjects in the control group was on any medication and all medication was withheld for 12 hours before the study in all patients. After an overnight fast, subjects swallowed, via the nose a $10 \mathrm{~F}$ Ryle's tube with a collapsed, plastic bag $(800 \mathrm{ml})$ sealed over the end, the side holes of the tube being within the bag. Within the lumen of the tube, positioned near its tip, was a pressure microtransducer (Gaeltec, Dingwall, Rosshire, Scotland) which was calibrated against a water for each subject, sitting and supine, based on the mean of the two values for each. These data were used to assess the effect of posture on gastric adaptive relaxation and also to compare the dynamic and static methods. Statistical analysis was by the Wilcoxon's signed-rank sum test for the former and the Mann Witney U test for the latter. The reproducibility of the technique was assessed in duplicate studies on separate days among eight healthy volunteers, seven of whom were drawn from the control group for this study. The eighth subject gave a history of reflux symptoms and was therefore excluded from the manometer to provide a full scale deflection of $50 \mathrm{~cm}$ water pressure. The transducer was interfaced with an amplifier and pen recorder (Gould Electronics Limited, Coventry, England) to record pressure changes against time. The bag was positioned manometrically in the corpus-fundus region of the stomach. A baseline recording was obtained during a 15 minute rest period. Air from a compressed air cylinder (British Oxygen Company, Guildford, Surrey, England) was delivered at a constant rate through an air flow meter and a safety valve to the Ryle's tube. This constant flow of air was used to distend the bag at a rate of $15 \mathrm{ml} /$ second for 30 seconds during which the pressure rise was recorded (dynamic recording). The recording was continued at this end volume for a further

TABLE Dynamic and static pressure indices $\left(\mathrm{cm} \mathrm{H}_{2} \mathrm{O}\right)$ comparing sitting and supine results. Values shown are medians (range). There were no significanl differences between sitting and supine results

\begin{tabular}{lllll}
\hline & $\begin{array}{l}\text { Control } \\
\text { Sitting }\end{array}$ & Supine & $\begin{array}{l}\text { Reflux } \\
\text { Sitting }\end{array}$ & Supine \\
\hline Dynamic & $11 \cdot 6(5 \cdot 7-17 \cdot 8)$ & $11 \cdot 9(7 \cdot 0-17 \cdot 8)$ & $8 \cdot 4(5 \cdot 8-12 \cdot 8)$ & $8 \cdot 9(5 \cdot 6-13 \cdot 7)$ \\
Static & $11 \cdot 5(5 \cdot 7-20 \cdot 1)$ & $10 \cdot 8(6 \cdot 5-20 \cdot 5)$ & $8 \cdot 7(5 \cdot 4-11 \cdot 3)$ & $8 \cdot 8(7 \cdot 3-14 \cdot 1)$ \\
\hline
\end{tabular}

150 seconds (static recording). The air was then aspirated with a syringe and the volume noted. This procedure was repeated at 15 minute intervals to provide four recordings for each subject, two each with the subjects sitting and supine. For each recording a dynamic pressure index was derived from the area under the curve during distension and a static pressure index was derived similarly, during the postinsufflation period of 150 seconds. These measurements were ascribed units in $\mathrm{cm} \mathrm{H}_{2} \mathrm{O}$ (Fig 1). A dynamic and static pressure index was derived control group for the main study. Reproducibility was expressed as the Spearman rank correlation coefficient calculated from the pressure indices obtained from paired studies. Finally, in view of the differences in ages and body weights between the two groups, a multiple regression model was created to see if there was any effect of these two variables on pressure index (Statistical Analysis System package, SAS Institute Inc, NC 27511, USA).

\section{Results}

The sitting and supine pressure indices obtained are summarised in Table I. There were no significant differences between the sitting and supine responses for either group in either the dynamic or static component of the studies. For subsequent analysis, sitting and supine results were combined to obtain single dynamic and static pressure indices for each subject, taking the mean of the four original observations. The dynamic and static pressure indices in the two groups are shown in Figure 2. Both dynamic and static pressure indices were significantly lower for patients in the reflux group when compared with the control group: $9 \cdot 1 \mathrm{~cm} \mathrm{H}_{2} \mathrm{O}$ versus $12 \cdot 7$ $\mathrm{cm} \mathrm{H}_{2} \mathrm{O}$ (median dynamic responses; $\mathrm{p}<0.01$ )

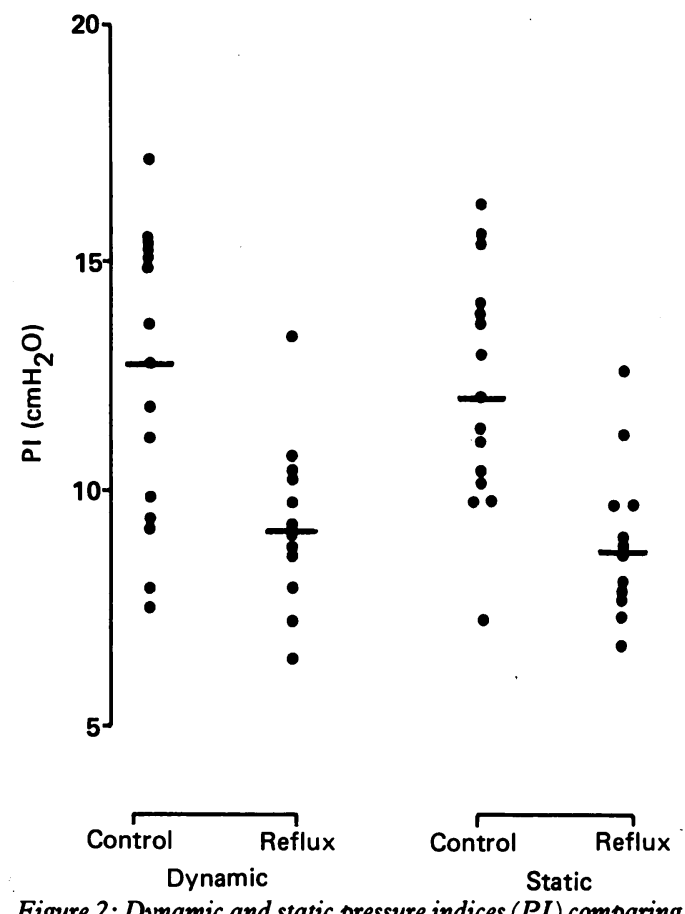

Figure 2: Dynamic and static pressure indices $(P I)$ comparing reflux and control groups. Each point represents the mean value for four observations for a single subject. Horizontal bars indicate median values. Both dynamic and static pressure indices were lower for the reflux group $(p<0.01)$. 


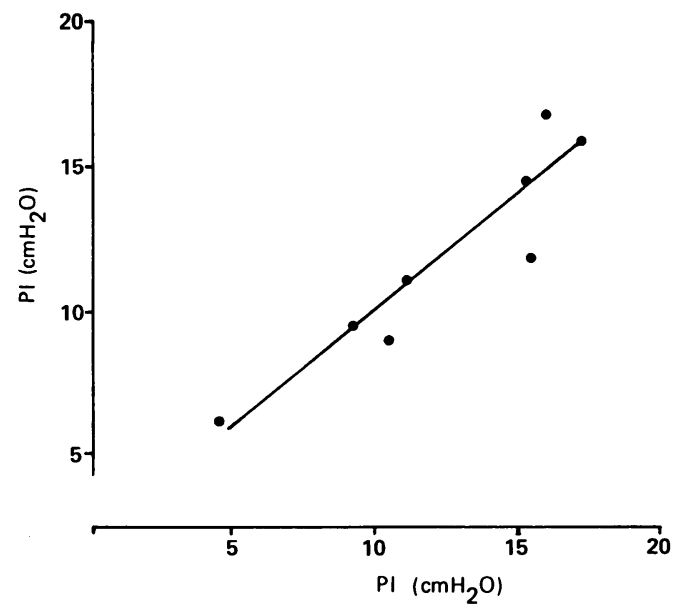

Figure 3: Linear plot of dynamic pressure index (PI ordinate) against dynamic pressure index (PI abscissa) obtained for the same subject in a repeat study, $n=8, r=0.93, p<0.01$ (Spearman rank correlation coefficient).

and $8.6 \mathrm{~cm} \mathrm{H}_{2} \mathrm{O}$ versus $12.0 \mathrm{~cm} \mathrm{H}_{2} \mathrm{O}$ (median static responses; $\mathrm{p}<0.01$ ).

The volumes (mean SD) of air aspirated were the same for the two groups (control $462(22) \mathrm{ml}$; reflux 456 (18) $\mathrm{ml}$; NS).

From the reproducibility studies the Spearman rank correlation coefficient for the dynamic pressure indices was $0.93(\mathrm{p}<0.01)$ and for the static pressure indices it was 0.82 $(p<0.05)$, for the eight healthy volunteers studied on two separate days (Fig 3). There was no significant correlation between pressure indices and ages $(r=-0 \cdot 29)$ or pressure indices and body weights $(r=-0 \cdot 17)$ among the two groups. Allowance for all the known covariates (age, weight, height, and sex) still yielded a significant difference between the control and reflux groups (partial ' $t$ ' in multiple regresssion $=-3.04,21 \mathrm{df}, \mathrm{p}<0.01,2$-sided $)$.

\section{Discussion}

In this study, posture has no identifiable effect on pressure indices for subjects in either group despite individual differences in erect and supine reflux episodes observed in $\mathrm{pH}$ studies upon patients in the reflux group. The methodology has permitted comparison between the dynamic and static techniques. Both gave similar results. In the reproducibility studies, however, the correlation between static pressure indices was somewhat poorer, indicating a greater degree of variability of static recordings. This may be a reflection of the variable contractile activity superimposed on the more prolonged static recordings.

Pressure indices showed an inverse correlation with age and body weight but this was not significant. We have considered the possibility that pressure indices differed in the two groups because of the different age and body weight profiles of the two groups. Multiple regression analysis indicates that this is not the case. Similarly, there was no difference in the distending volumes between the two groups. The presence of hiatus hernia in four of the 12 patients did not appear to produce different results in this subgroup. We have not studied patients with large hiatus hernias but might have expected such subjects to show spuriously high pressure responses if the bag became incarcerated within the hiatus hernia or displaced into the distal stomach.

The numbers of control subjects and patients studied were quite small and there is some overlap in the results obtained from the two groups (Fig 2). The difference was, nevertheless, statistically significant and the results thus suggest that patients with gastrooesophageal reflux exhibit significantly lower gastric pressure responses to distension compared with normal healthy subjects. At first sight this finding might appear somewhat paradoxical. It might be assumed that, if anything, the gastric pressure response should be increased in patients with gastrooesophageal reflux. It should be remembered, however, that gastric distension produces a fall in resting lower oesophageal sphincter pressure ${ }^{10}$ and an increase in transient sphincter relaxations. ${ }^{5}$ There is evidence furthermore, that the lower oesophageal sphincter and the gastric corpus-fundus relax as a functional, physiological, unit. ${ }^{12}$ It is not unreasonable to suppose, therefore, that reflux disorders may be characterised by low pressure responses throughout this unit while this condition is still compatible with the development of a gastrooesophageal pressure gradient favouring reflux. It may be relevant to note that a similar neural pathway is probably involved in both lower oesophageal sphincter relaxation ${ }^{13}$ and gastric adaptive relaxation. ${ }^{8}$ The neural pathway for gastric adaptive relaxation is a vagovagal reflex. The present study thus provides supportive evidence for an abnormality of the vagovagal inhibitory pathway involved. Indeed, abnormalities of other aspects of vagal function have also been demonstrated in some patients with gastrooesophageal reflux. ${ }^{14}$

Expulsion of liquid chyme from the stomach is largely dependent on the gastroduodenal pressure gradient; ${ }^{15}$ an abnormally low intragastric pressure during gastric distension would be expected to delay gastric emptying. The previously reported findings of delayed gastric emptying of liquids ${ }^{16} 17$ and solids ${ }^{6}$ in patients with gastrooesophageal reflux, may be explained at least in part by the results of the present study.

This abnormality of corpus-fundus motility in patients with gastrooesophageal reflux provides further supportive evidence for the idea that gastrooesophageal reflux is part of a generalised foregut motility disorder.

This study was supported by the Mersey Regional Health Authority Research Scheme No. 548. The work described in this paper has been described in abstract form (Gut 1987; 28: A1376, Brf Surg 1988; 75: 614)

1 Velasco N, Hill L, Gannan R, Pope C. Gastric emptying and gastro-oesophageal reflux. Effects of surgery and correlation with oesophageal motor function. Am $\mathcal{Y}$ Surg 1982; 144: 58 62.

2 Ferguson $M$, Ryan J, Little A, Skinner D. Esophageal emptying and acid neutralisation in patients with symptoms of esophageal reflux. Ann Surg 1985; 201: 728-35.

3 Hillemeier A, Grill B, McCallum R, Gryboski J. Esophageal and gastric motor abnormalities in gastrooesophageal reflux and gastric motor abnormalities in gastrooesoph
during infancy. Gastroenterology 1983; 84: 741-6.

4 Dodds W, Hogan W, Helm J, Dent J. Pathogenesis of reflux oesophagitis. Gastroenterology 1981; 81: 376-94.

5 Holloway R, Hongo M, Berger K, McCallum R. Gastric distension: a mechanism for postprandial gastrooesophageal distension: a mechanism for postprandial
reflux. Gastroenterology 1985; 89: 779-84. 
6 McCallum R, Berkowitz D, Lerner E. Gastric emptying in patients with gastroesophageal reflux. Gastroenterology 1981 ; 80: 285-91.

7 Behar J, Ramsby G. Gastric emptying and antral motility in reflux esophagitis. Effect of oral metoclopramide. Gastro$74 ; 253-6$

8 Jahnberg T, Martinson J, Hulten L, Fasth S. Dynamic gastric response to expansion before and after vagotomy. Scand $\mathcal{F}$ Gastroenterol 1975; 10: 593-8.

9 Stadaas J. Intragastric pressure/volume relationship in the normal human stomach. Scand $\mathcal{F}$ Gastroenterol 1975; 10: 135-40.

10 Muller-Lissner S, Blum A. Fundic pressure rise lowers lower esophageal sphincter pressure in man. Hepatogastroenterol 1982; 29: 151-2.

11 Cannon W, Lieb C. The receptive relaxation of the stomach. Am f Physiol 1911; 29: 267-73.
12 Lind J, Duthie H, Schlegel J, Code C. Motility of the gastric fundus. Am F Physiol 1961; 201: 197-202.

13 Martin C, Patrikios J, Dent J. Abolition of gas reflux and transient lower esophageal sphincter relaxation by vagal blockade in the dog. Gastroenterology 1986; 91: 890-6.

14 Ogilvie A, James P, Atkinson M. Impairment of vagal function in reflux oesophagitis. $Q \mathcal{F}$ Med $1985 ; 213: 61-74$.

15 Wilbur B, Kelly K. Effect of proximal gastric, complete gastric and truncal vagotomy on canine gastric electrical activity, motility and emptying. Ann Surg 1973; 178: 295303.

16 Hillemeier A, Lange R, McCallum R, Seashore J, Gryboski J Delayed gastric emptying in infants with gastroesophageal reflux. F Pediatr 1981;98: 190-3.

17 Baldi F, Corinaldesi $R$, Ferrarini F, Stanghellini V, Miglioli $M$, Barbara L. Gastric secretion and emptying of liquids in reflux esophagitis. Dig Dis $S$ ci 1981; 26: 886-9.

\section{FINAL ANNOUNCEMENT}

The Wirld Comeresenes

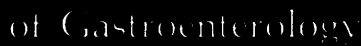

Aus:unt 20th-314t, 1000)

Sidne Suntialia 9th Congress of Gastroenterology

7th Congress of Digestive Endoscopy

4th Congress of Colo-Proctology

For copies of the Final Announcement/Registration Forms, contact:

The World Congresses of Gastroenterology Secretariat P.O. Box 386

St. Leonards, NSW, Australia 2065

Tel. Int. $+612-438-4644 \quad$ Fax Int. $+612-439-7546$ 
28 Fujii M, Sogamura K, Sabno K, Nakai M, Sugita K, Hinuma $Y$. High-affinity receptor-mediated internalization and degradation of interleukin 2 in human T-cells. $\mathcal{F}$ Exp Med 1986; 163: $550-62$.

29 Smith KA, Cantrell DA. Interleukin 2 regulates its own receptor. Proc Natl Acad Sci USA 1985; 82: 864-8.
30 Rubin LA, Jay G, Nelson DL. The released interleukin 2 receptor binds interleukin 2 efficiently. $\mathcal{F}$ Immunol 1986 137: $3841-4$

31 Baker K, Jewell DP. Cyclosporin for the treatment of severe inflammatory bowel disease. Aliment Pharmacol Therap 1989; 3: 143-9.
Correction Abnormal gastric adaptive relaxation in patients with gastrooesophageal reflux by M N Hartley, S J Walker, C R Mackie. May 1990 issue, pp 500-3. In this article several lines of text in the Methods section were transposed. The corrected text appears below.

\section{Methods}

SUBJECTS

Fifteen normal healthy volunteers were studied. These were 13 men and two women, with a median age of 30 years (range 22-41) and a median body weight of $70 \mathrm{~kg}$ (range $50-79$ ) kg. Twelve patients with symptomatic gastrooesophageal reflux were studied. They were eight men and four women, with a median age of 48 years (range 23-65) and a median body weight of $77 \mathrm{~kg}$ (range $60-92 \mathrm{~kg}$ ). All subjects in the control group were asymptomatic. Among patients in the reflux group, eight were complaining of regurgitation, 11 of heartburn, and four of dysphagia.

The presence of pathological gastrooesophageal reflux was confirmed in all patients in the reflux group by 24 hour ambulatory oesophageal $\mathrm{pH}$ monitoring. Pathological gastrooesophageal reflux was defined as the presence of one or more of the following criteria: total reflux time greater than $6 \%$, erect reflux time greater than $8 \%$, supine reflux time greater than $2 \%$; more than two reflux episodes longer than five minutes. A reflux episode was defined as a drop in $\mathrm{pH}$ to 4 or less.

Endoscopy showed macroscopic oesophagitis in seven patients, associated with a hiatus hernia in four patients. Five patients had no abnormality at endoscopy. None of the subjects in the control group was on any medication and all medication was withheld for 12 hours before the study in all patients. After an overnight fast, subjects swallowed, via the nose a 10F Ryle's tube with a collapsed, plastic bag $(800 \mathrm{ml})$ sealed over the end, the side holes of the tube being within the bag. Within the lumen of the tube, positioned near its tip, was a pressure microtransducer (Gaeltec, Dingwall, Rosshire, Scotland) which was calibrated against a water manometer to provide a full scale deflection of
$50 \mathrm{~cm}$ water pressure. The transducer was interfaced with an amplifier and pen recorder (Gould Electronics Limited, Coventry, England) to record pressure changes against time. The bag was positioned manometrically in the corpus-fundus region of the stomach. A baseline recording was obtained during a 15 minute rest period. Air from a compressed air cylinder (British Oxygen Company, Guildford, Surrey, England) was delivered at a constant rate through an air flow meter and a safety valve to the Ryle's tube. This constant flow of air was used to distend the bag at a rate of $15 \mathrm{ml} /$ second for 30 seconds during which the pressure rise was recorded (dynamic recording). The recording was continued at this end volume for a further 150 seconds (static recording). The air was then aspirated with a syringe and the volume noted. This procedure was repeated at 15 minute intervals to provide four recordings for each subject, two each with the subjects sitting and supine. For each recording a dynamic pressure index was derived from the area under the curve during distension and a static pressure index was derived similarly, during the postinsufflation period of 150 seconds. These measurements were ascribed units in $\mathrm{cm} \mathrm{H}_{2} \mathrm{O}$ (Fig 1). A dynamic and static pressure index was derived for each subject, sitting and supine, based on the mean of the two values for each. These data were used to assess the effect of posture on gastric adaptive relaxation and also to compare the dynamic and static methods. Statistical analysis was by the Wilcoxon's signed-rank sum test for the former and the Mann Witney U test for the latter. The reproducibility of the technique was assessed in duplicate studies on separate days among eight healthy volunteers, seven of whom were drawn from the control group for this study. The eighth subject gave a history of reflux symptoms and was therefore excluded from the control group for the main study. Reproducibility was expressed as the Spearman rank correlation coefficient calculated from the pressure indices obtained from paired studies. Finally, in view of the differences in ages and body weights between the two groups, a multiple regression model was created to see if there was any effect of these two variables on pressure index (Statistical Analysis System package, SAS Institute Inc, NC 27511, USA). 